\title{
Analysis of Slope Stability and Disaster Law under Heavy Rainfall
}

\author{
Pengfei Guo $\mathbb{D}$, Yadi Yuan, Yanyan Peng, Haijiag Zhang, and Yongxu Zhao
}

School of Civil Engineering, Shaoxing University, Shaoxing 312000, China

Correspondence should be addressed to Pengfei Guo; gpf20101989@163.com

Received 6 January 2021; Revised 7 February 2021; Accepted 12 February 2021; Published 23 February 2021

Academic Editor: Feng Xiong

Copyright ( 2021 Pengfei Guo et al. This is an open access article distributed under the Creative Commons Attribution License, which permits unrestricted use, distribution, and reproduction in any medium, provided the original work is properly cited.

\begin{abstract}
Based on this, the slope stability and disaster law under the condition of heavy rainfall are studied. With the slope of Shangge Village as the background, the slope stability under the condition of heavy rainfall is deeply studied through theoretical analysis, laboratory physical model experiment, and numerical simulation. Results showed that due to the heavy rainfall within $2 \mathrm{~h}$, the deformation of the slope is not obvious in the rain $2 \mathrm{~h} \sim 7 \mathrm{~h}$ period, first of all in the position of slope toe of slope stress raiser; As the rainfall continued, the infiltration of rainwater led to weakening of the rock mass strength, and the cracks in the slope fracture zone further expanded and extended to the top of the slope. After 7 hours of rainfall, the slope formed a sliding surface. The physical model experiment and the numerical simulation results are in good agreement, which can provide the basis for slope reinforcement under heavy rainfall conditions and have important scientific significance and social value for the reasonable site selection of housing construction, transportation network, and disaster prevention and mitigation in coastal areas.
\end{abstract}

\section{Introduction}

Since the middle of the 20th century, with the continuous growth of China's population, the continuous expansion of the scope of human activities, the increasingly serious transformation and destruction of the geological environment, coupled with the impact of global climate change and other factors, and the frequency of geological disasters remain high, causing a large number of casualties and large economic losses. In the report to the 19th National Congress of the Communist Party of China (CPC), it was proposed to "strengthen the prevention and control of geological disasters". Statistics of geological disasters of the Ministry of Land and Resources in the past three years [1-3] are shown in Table 1. In recent years, geological disasters are highly frequent, and a series of problems emerge that need to be solved urgently. Landslide is the worst-hit area of geological disasters, which was the highest occurrence frequency and harms one of the largest and the widest influence scopes of geological disasters; in 2019, China geological disaster composition, for example, China accounted for $68.27 \%$ of the total number of disasters, geological disasters in landslide proportion far above other disasters. On March 15, 2019, in Linfen city,
Shanxi Province, Ningxiang County, the large landslides occur, about 70000 cubic meters of slope sliding failure happens; the top more buildings have been destroyed; 20 people were killed and 13 injured, and there was a direct economic loss of more than 700 ten thousand yuan. On July 23, 2019, a massive landslide occurred in Shuicheng County, Liupanshui city, Guizhou Province. Due to the heavy rainfall in the early days, the rain penetrated into the slope and the landslide occurred in the evening of the same day. The landslide volume was about 300,000 cubic meters, causing 43 deaths, 9 missing, and 11 injured, and the direct economic loss amounted to 190 million yuan [3]. Most of the provinces along the southeast coast of China are dominated by mountains and hills with complex geological conditions and high intensity of human engineering activities, making them one of the provinces with frequent occurrences of geological disasters in China $[4,5]$. Taking Zhejiang province as an example, Zhejiang province is a province with mountains and hills as the main terrain. The available area of the plain is less, and it is a typical land structure with "seven mountains, one water, and two fields", which is prone to landslides. At the same time, China's vast sea area is one of the countries with the most frequent landfall and the most severe typhoon 
TABLe 1: Statistics of geological disasters in China from 2017 to 2019.

\begin{tabular}{cccccc}
\hline Year & $\begin{array}{c}\text { Number of } \\
\text { occurrences/times }\end{array}$ & $\begin{array}{c}\text { Number of } \\
\text { deaths/persons }\end{array}$ & $\begin{array}{c}\text { Number of } \\
\text { missing/persons }\end{array}$ & $\begin{array}{c}\text { Number of } \\
\text { injured/persons }\end{array}$ & $\begin{array}{c}\text { Direct economic } \\
\text { loss/100 million yuan }\end{array}$ \\
\hline 2017 & 7122 & 327 & 25 & 173 & 35.4 \\
2018 & 2966 & 105 & 7 & 73 & 14.7 \\
2019 & 6181 & 211 & 13 & 75 & 27.7 \\
\hline
\end{tabular}

damage in the world. Typhoon often causes heavy rainfall; typhoon attacks in Zhejiang province every year; as the global climate has changed dramatically, the frequency, scale, and harm of the typhoon are becoming bigger and bigger, and the resulting rainfall is in constant increase; during the typhoon, rainfall intensity is big; short history, etc. of landslides are usually formed in soft debris and weathering, induce the formation of the landslide is ephemeral, no hysteresis, at the same time because of the uncertainty of the typhoon, variability, for regional landslide disaster prevention, and early warning with great challenges. Rainfall mainly changes the structure and mechanical properties of rock and soil mass in surface runoff, seepage, and other ways, which leads to the reduction of shear strength and makes the situation of landslide prevention and control more serious. At present, the mechanism and law of rock slope disaster under the influence of heavy rainfall, monitoring and warning model and technology are not very clear [6-8]. Therefore, it is of great scientific significance and social value to analyze the stability of rock slope under heavy rainfall and study the law of disaster for housing construction, reasonable site selection of transportation network, and disaster prevention and mitigation in coastal areas.

The study of slope stability has a history of hundreds of years. British scholar Ryle [9] first put forward the term "landslide" in his book "Principles of Geology" in 1833 and pointed out that groundwater is an important factor affecting the occurrence of the landslide. Since then, scholars at home and abroad have carried out long-term research on this. In the early study of landslide stability, the geological and hydrologic environment, the occurrence law, and change failure mechanism of landslide are mainly expounded. Later, with the rapid development of highways, railway, and other infrastructure, slope instability occurs frequently, and rock mechanics emerges at the right moment. With the continuous development of rock mechanics theory, the research on rock landslides is also gradually deepening. Soil mechanics and rock mechanics are the two theoretical bases for the study of the stability of landslides [10]. Since the 1980s, many rock mechanics experts and scholars at home and abroad have devoted themselves to the study of slope stability. A.W.Hop [11], a famous British soil mechanics expert, first proposed the slope stability calculation method, which has been widely used in engineering. Zheng et al. [12] improved the Sarma method based on the new interbar shear equation. The modified Sarma method considers that the shear strength of the bar interface and the sliding surface have different reduction coefficients. The improved Sarma method is superior to the Sarma method and can obtain a more reasonable safety coefficient value. With the development of com- puter technology and geotechnical mechanics, various complicated numerical simulation methods have been widely used in the study of the landslide. Numerical simulation [13, 14] has made great progress in the field of slope stability analysis. Zhang et al. [15] used FLAC3D to conduct threedimensional elastic-plastic numerical analysis on a slope rock mass of Pengshui Hydropower Station, analyzed the influence of slope excavation on its overall stability, and thus obtained the stability of the slope. Based on FLAC3D elastoplastic analysis, Liu et al. [16] proposed a method for shear strain increment searching slope slip surface in view of slide surface search and quantitative evaluation of stability in slope dynamic analysis and used the vector and methods to calculate the safety factor. Xu et al. [17] used the RFPA3D software to study the initiation, evolution, expansion, interaction, and penetrating mechanism of microfractures in the failure process of qualitative slope under three-dimensional conditions and revealed the overall failure mode of the slope. Caine [18] first proposed the concept of rainfall threshold in 1980 and expounded the relationship between rainfall intensity and rainfall time and the occurrence of landslides. This method has an important impact on the study of rainfallinduced landslide disasters. Wu et al. and Xie et al. [19, 20] in the Ming Dynasty used accumulated rainfall to determine the critical rainfall of typhoons and rainfall-type landslides and proposed that the accumulated rainfall was $150 \mathrm{~mm}$ as the threshold. Zhao et al. [21] studied the rainfall threshold curve of the western region of Hubei based on the continuous time period when the rainfall was higher than $0.1 \mathrm{~mm}$ per hour and proposed the corresponding rainfall threshold curve.

In the existing research, the stability analysis of slope and rainfall slope has been relatively in-depth; the research results have provided the basis for landslide early warning and slope reinforcement, but there are still some problems to be solved. At present, the research on the slope stability of rainfall is mainly focused on the slope stability under the conditions of moderate and light rain. With the constant change of global climate and frequent occurrence of extreme weather, there is little research on slope stability under heavy rainfall conditions. Thus, it is essential to study the slope stability under heavy rainfall.

\section{Engineering Background}

The slope was located in the "patio" mountain in the northwest of Panan County, Zhejiang province, and the geographical coordinates of the center point were $120^{\circ} 26^{\prime} 32^{\prime \prime}$ east longitude. In north latitude $29^{\circ} 00^{\prime} 17^{\prime \prime}$, the front edge of 


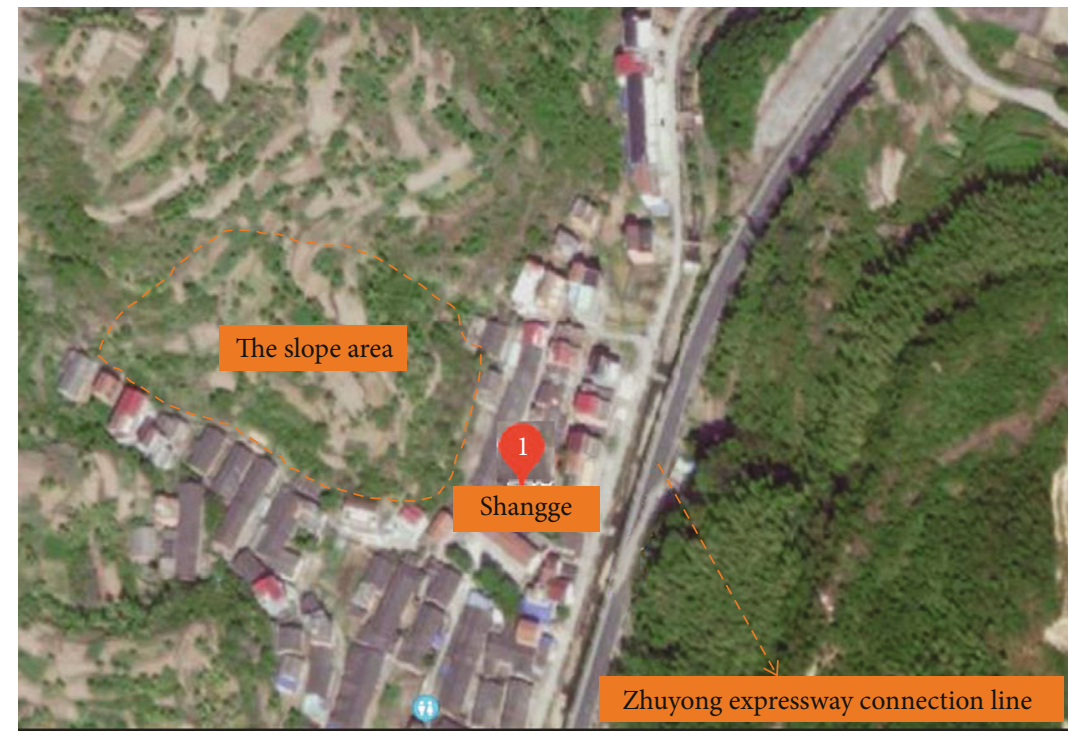

FIgUre 1: The geographical location of the slope of the Shangge Village.

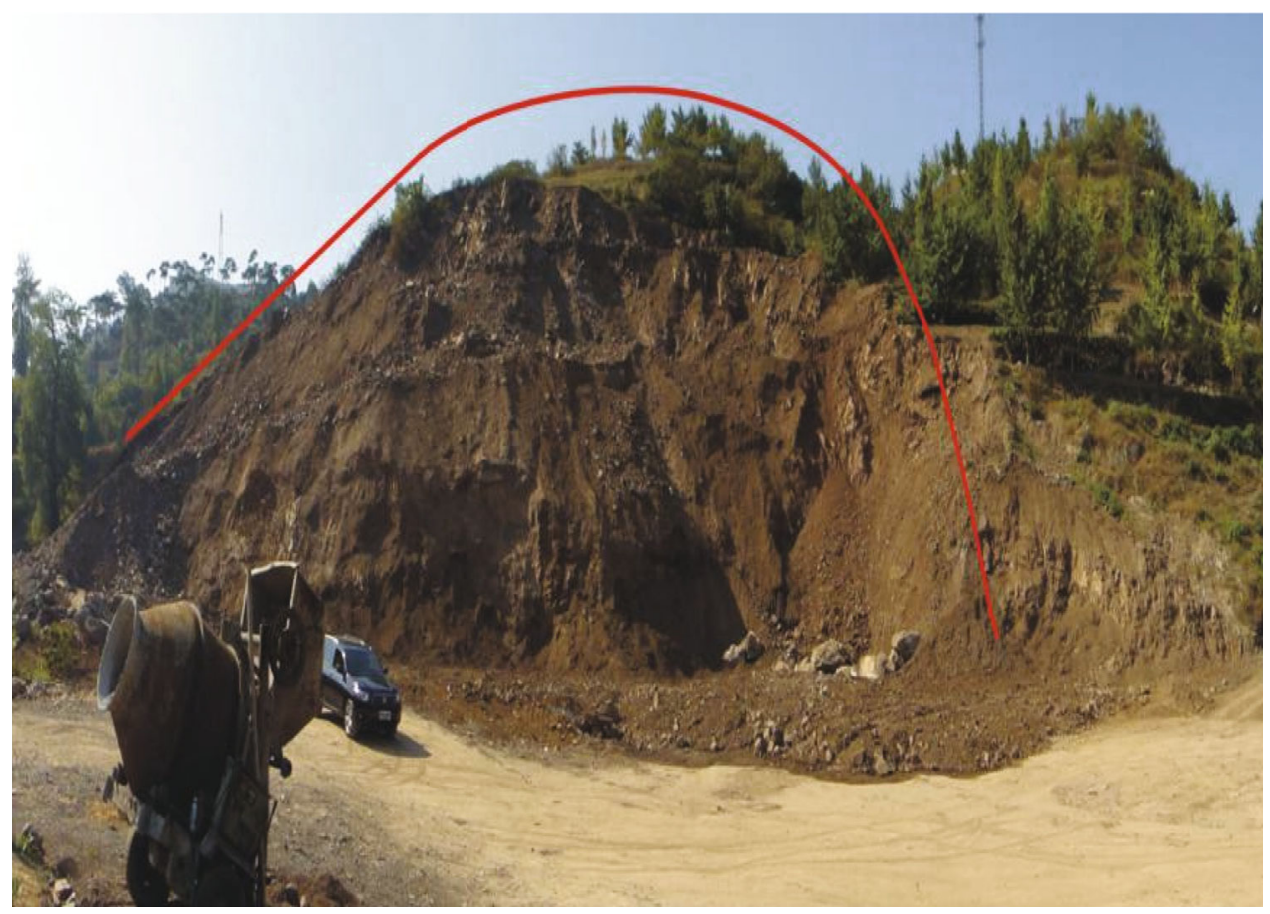

Figure 2: Overall view of the Shangge Village slope.

the slope is close to the Zhuyong expressway connection line (see Figure 1). The overall terrain of the slope descends naturally from northwest to southeast, and the ridge is in a long strip. The highest elevation in the area is $467.73 \mathrm{~m}$, the lowest is about $358.24 \mathrm{~m}$, and the relative elevation difference is about $110 \mathrm{~m}$. The Shangge slippery slope is located in Yunshan tourist resort, which is one of the twenty-one provincial resorts in Zhejiang province. The Shangge Village landslide is at the entrance of the resort, and the sloping front expressway connection line is the main passage from the old city to the new city of Panan County, affecting the development and construction of the resort. The area belongs to the subtropical monsoon climate zone, warm wet, over the four seasons, abundant rainfall, annual average temperature of $13.9 \sim 17.4^{\circ} \mathrm{C}$, annual average frostfree period of 200 243 days, years of average rainfall of $1550 \mathrm{~mm}$, uneven distribution of precipitation in the years, rainfall concentrated in 3 6 months of rainy season, and 7 9 months affected by the typhoon, accompanied by rain, autumn, winter, drought, and dry.

The plane shape of the Shangge Village slope is approximately "rectangular" (see Figure 2). The main sliding 


\begin{tabular}{|c|c|c|}
\hline Rock signature & & Thickness \\
\hline $\begin{array}{l}\text { Pebbled } \\
\text { cohesive soil }\end{array}$ & GISA-A & $\frac{0.4 \sim 3.3}{0.8}$ \\
\hline $\begin{array}{c}\text { Strongly } \\
\text { weathered tuff }\end{array}$ & $\mid$ & $\frac{4.1 \sim 10.9}{5.7}$ \\
\hline $\begin{array}{c}\text { Moderately } \\
\text { weathered tuff }\end{array}$ & & $\frac{2.5 \sim 8.6}{4.9}$ \\
\hline $\begin{array}{l}\text { Interlaminar } \\
\text { fracture zone }\end{array}$ & A & $\frac{1.6 \sim 3.3}{2.1}$ \\
\hline $\begin{array}{c}\text { Moderately } \\
\text { weathered sandstone }\end{array}$ & & $\frac{4.3 \sim 13.3}{10.6}$ \\
\hline $\begin{array}{c}\text { Moderately } \\
\text { weathered tuff }\end{array}$ & & $\frac{12.6 \sim 26.2}{22.3}$ \\
\hline
\end{tabular}

FIgURE 3: Histogram of stratigraphic lithology.

direction is about $140^{\circ}$, the axis is about $255.0 \mathrm{~m}$ long and $100.0 \mathrm{~m}$ wide, and the area is about $2.6 \times 104 \mathrm{~m}^{2}$. The maximum thickness of the landslide is $35.5 \mathrm{~m}$, the average thickness is about $18 \mathrm{~m}$, and the volume of the landslide is about $47 \times 104 \mathrm{~m}^{3}$, belonging to the medium and middle rock landslide.

The slope rock and soil are divided into six engineering geological layers from top to bottom: the first layer is gravelbearing cohesive soil, which is distributed on the surface of the mountain slope, with a thickness of $0.4 \sim 3.30 \mathrm{~m}$, grayishyellow, gray, slightly wet, and slightly dense-medium-dense shape, with a small number of plant roots in the shallow part; the gravel is composed of weathered sandstone, tuff, andesite porphyry, and angular, with a diameter of $2 \sim 5 \mathrm{~cm}$, the content ranges from 15 to $45 \%$, and the distribution is uneven. The second layer is strongly weathered tuff: gray, grayish-yellow, loose, and slightly dense to dense, with developed weathered fissures; the core is in the shape of fragments, fragments interbedded with soil, and the content of fragments is $>50 \%$, and the diameter is $2 \sim 8 \mathrm{~cm}$; the rock is soft, and the layer thickness is $4.10 \sim 10.9 \mathrm{~m}$. The third layer is moderately weathered tuff: gray-purple and massive structure; the core is relatively fragmented, mainly short columnar, and a small amount of long columnar; the maximum section length is $25 \mathrm{~cm}$, the rock is hard, and the thickness is $2.50 \sim 8.60 \mathrm{~m}$. The fourth layer is an interlayer broken zone, with mixed colors, mainly gray and dark red, and the core is extremely broken, in the shape of soil interspersed with broken blocks, soil (gravel-bearing clay soil and cohesive soil-gravel sand), and broken blocks. The rock is extremely soft, and it is easy to saturate and soften in contact with water. The fifth layer is moderately weathered siltstone. The sandstone is dark red, grayish purple, silty fine sand structure, and mediumthick layered; the core is relatively broken and columnar, and the node length is $5 \sim 34 \mathrm{~cm}$. The core is relatively com- plete and columnar. It is a hard rock with a thickness of about $19.40 \mathrm{~m}$. The lithology of the sixth layer is basically the same as that of the third layer, and its thickness is about 12.60 26.20 m (see Figure 3).

\section{Theoretical Analysis}

The propagation of internal cracks in a slope is an extremely complex process, which is mainly manifested in three aspects: crack initiation, propagation, and penetration. Due to the slope unloading, the internal cracks in the rock mass will be temporarily closed under the influence of its own weight. With the excavation unloading, the stress will be released. Stress concentration will begin to occur on the new open surface, and the rock mass will be formed. Cracking occurs after the stress concentration reaches a certain level. The cracking criterion [22] is as follows:

$$
\tau=\tau^{\prime}+f \sigma=\frac{2-v}{2 M} \sqrt{\frac{\pi}{2}} \frac{k^{\prime}}{\sqrt{2 a}},
$$

where $\tau$ is the shear force, $f$ is the shear friction coefficient, $M$ is the experimental constant, $2 a$ is the crack width, $k^{\prime}$ is the fracture toughness, and $\sigma$ is the normal stress.

After the cracks in the rock body begin to crack, it will inevitably cause stress release, leading to stress redistribution, and the stress concentration at the crack tip (stress intensity factor K) directly affects the crack propagation. When the stress intensity factor at the crack tip increases, the crack further expands. Otherwise, the crack propagation stops. The prerequisite for crack propagation is that the released elastic potential energy can meet the increased surface energy required to form a crack [23].

$$
U=U_{1}+U_{2}-W
$$

where $U$ is the energy of the unit body, $U_{1}$ is the elastic potential energy stored in the unit body, $U_{2}$ is the elastic energy related to crack propagation, and $W$ is the work done in the expansion process.

According to the Hoek-Brown criterion, when the unloading rock mass fails, it is necessary to satisfy the relationship formula of the principal stress of the rock mass failure [24].

$$
\sigma_{1}=\sigma_{3}+\sqrt{m \sigma_{0} \sigma+s \sigma_{0}^{2}}
$$

where $\sigma_{0}$ is the uniaxial compressive strength, $\sigma_{1}$ is the maximum principal stress, $\sigma_{3}$ is the minimum principal stress, and $m$ and $s$ are the rock material constant depending on the rock properties.

When the rock mass integrity factor is $<1$, the penetration criterion at this time is [24]

$$
\sigma_{t_{\max }}=\frac{\sigma_{0}}{2}\left(m-\sqrt{m^{2}+4 s}\right) .
$$




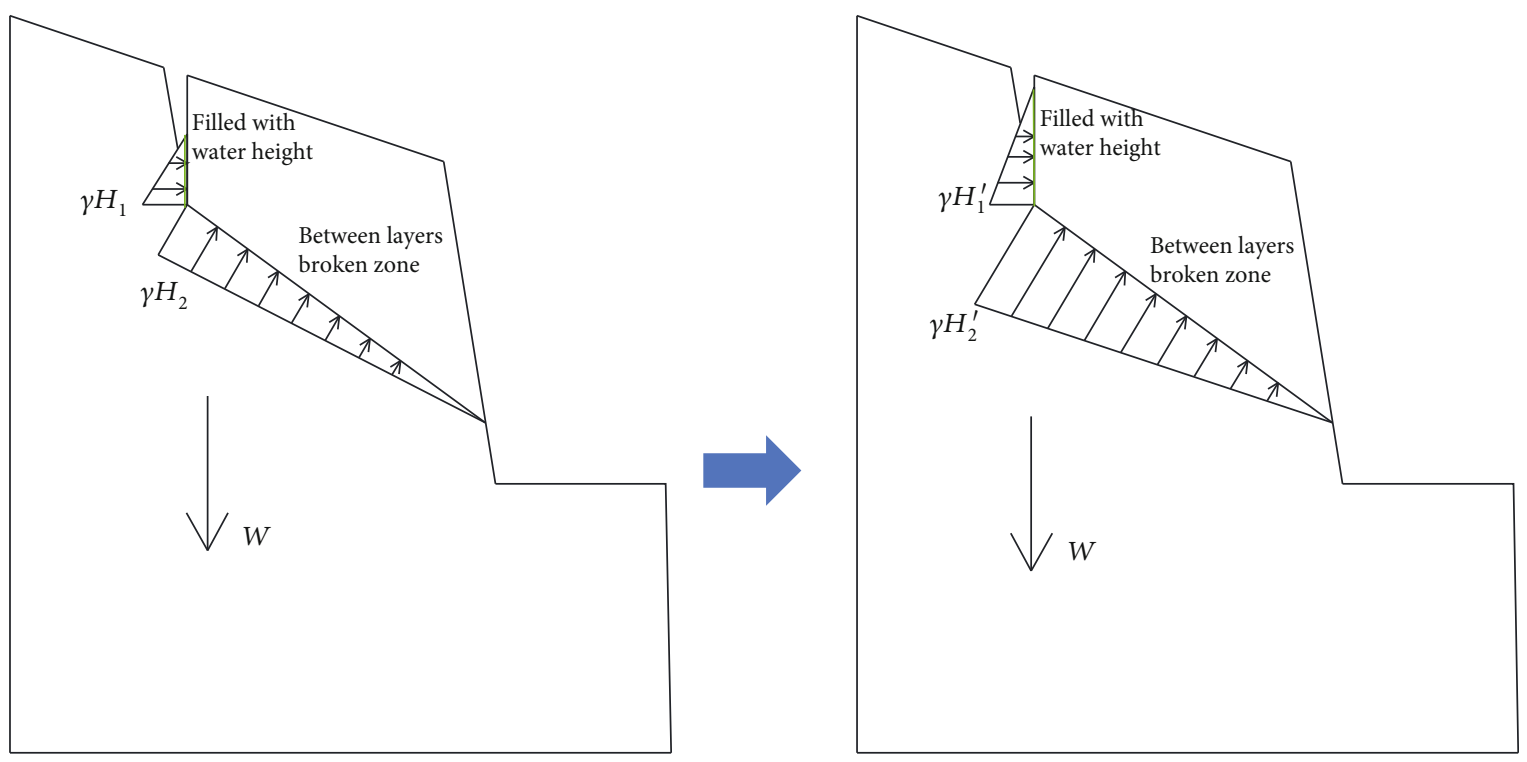

Figure 4: Schematic diagram of fracture water pressure.

When cracks are through the overall carrying capacity of the rock mass to limit the equilibrium state, the stress on the surface of the rock mass of sharply reduced, unstable rock mass, sliding phenomenon may occur at any time, and in the process of crack propagation through the complete degree of the damaged rock mass, the rock mass integrity level directly affects the stability of rock mass. Rock slope at the beginning of the deformation of slope body inside will not appear immediately to complete the penetration area, and the slope tends to form a certain partial loose peristalsis, and internal cracks will be on in the direction of slope surface international airport development; under the influence of gravity stress, the internal crack is expanding, as well versed in, eventually loose along the slip surface, until the occurrence of landslides.

The internal cracks of the slope penetrate, leading to slope instability at any time. Under rainfall conditions, due to gravity and matrix suction, rainfall infiltrates the unsaturated rock and soil of the slope, and the outer rock and soil gradually become saturated. As the rainfall continued, the rain continued to infiltrate and expand downward. The process of rainfall infiltration exacerbates the instability of the slope, especially when the rainfall reaches a certain condition, and it is easy to induce landslides. First, the rainfall increases the weight of the slope, which leads to an increase in the sliding force; secondly, the rainfall infiltration will have a certain impact on the strength of the rock and soil, resulting in a sharp decrease in the internal friction angle and cohesion, which will lead to the safety of the slope. The coefficient is reduced. When the antisliding force of the slope $<$ the sliding force, the slope starts to slide along the weak structural surface, forming a landslide. In the rainfall slope, the influence of water on the slope is shown in Figure 4.

After a long time of rainfall, the fracture water pressure in the rock and soil mass is generated, which is mainly manifested in the hydrostatic pressure on the fractures in the rock and soil mass and the uplift pressure of the interlayer fracture zone. The hydrostatic pressure is triangulated, with zero above and zero below. When the depth is $\mathrm{H}$, the hydrostatic pressure is $\gamma H$, and a certain thrust will be generated in the horizontal direction. The hydraulic gradient determines the magnitude of the force in the horizontal direction. The Yang pressure is distributed along the cracks of the interlayer fracture zone, and the size is zero at the slope surface. When the position of the interlayer fracture zone is disposed, the maximum is $\gamma H$. The uplift pressure reduces the principal stress of the rock mass to a certain extent. Under the combined influence of hydrostatic pressure and uplift pressure, the stability of the slope decreases and landslides are prone to occur.

For the initially dry rock and soil body, when rainfall infiltrates, due to the slope of the slope, the rainfall infiltration rate is

$$
i=K_{s} \frac{Z_{f} \cos \beta+S_{f}}{Z_{f}},
$$

where $i$ is the rainfall infiltration rate, $K_{s}$ is the permeability coefficient under saturation, $Z_{f}$ is the depth of the wet front perpendicular to the slope, $S_{f}$ is the matrix suction head, and $\beta$ is the slope angle.

In the natural state, the slope, rock, and soil are unsaturated, and the rainfall intensity is less than the infiltration capacity of the rock and soil. Rain will infiltrate all of it. As time goes by, the further infiltration of rainfall will form a wet front at a certain moment. The rainfall at this time is $q$; then, the rainfall infiltration rate at this time is $q \cos \beta$, and substitute the above formula to get the wet front depth $Z_{p}$ at this time.

$$
Z_{p}=\frac{S_{f}}{\left(q / K_{s}-1\right) \cos \beta} .
$$




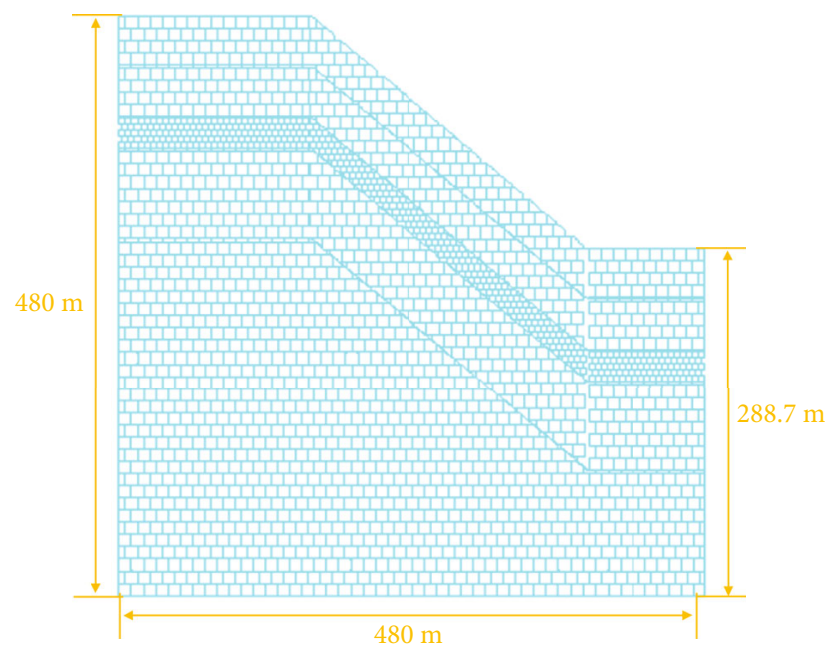

Figure 5: Simplified model of slope.

At this time, the cumulative rainfall infiltration $I_{p}$ is

$$
I_{P}=\left(\theta_{S}-\theta_{i}\right) Z_{P}=\frac{\left(\theta_{f}-\theta_{i}\right) S_{f}}{\left(q / K_{S}-1\right) \cos \beta}
$$

where $\theta_{s}$ is the saturated volumetric water content and $\theta_{i}$ is the natural volumetric water content.

After the wet front is formed in the slope body, the upper part of the wet front is in a saturated state, and the rainfall intensity on the surface of the slope is higher than the infiltration capacity of rainwater, which will form a current on the slope surface and gather at the foot of the slope. For shortterm rainfall, due to its short rainfall time and low rainfall intensity, the amount of rain infiltrated within a certain period time in the slope body is small, which has a limited impact on the stability of the slope. When the rainfall lasts for a long time and the rainfall intensity increases the internal slope in a very short period of time, the amount of infiltration has increased sharply, which has a great impact on the stability of the slope.

\section{Numerical Simulation of Slope Stability under Heavy Rainfall}

4.1. Establishment of the Slope Model. To further study the slope stability analysis and catastrophe law under heavy rainfall conditions, the finite element calculation method is difficult to simulate the failure process and form of rock materials, and the discrete element method can realize the transition process from continuous to discontinuous. Therefore, the discrete element software is selected UDEC, as the numerical simulation software, builds a model based on the actual engineering geology with a length of 480 meters in the horizontal direction, 480 meters in the vertical direction on the left side, and 288.7 meters in the vertical direction on the right side. The simplified slope model is established as shown in Figure 5. As shown, the model material uses the Mohr-Coulomb model, the joints uses Coulomb sliding model, and the calculation unit uses a triangular mesh. The

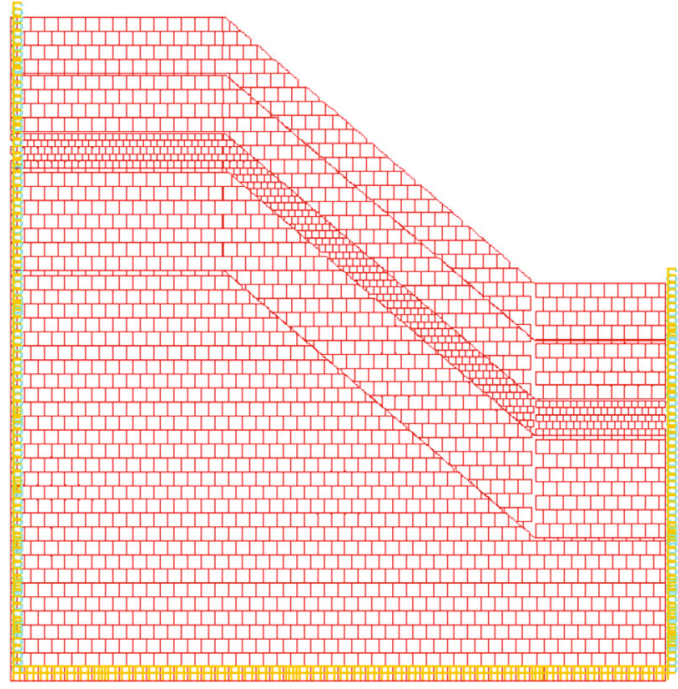

FIGURE 6: Schematic diagram of model boundary constraints.

lower boundary of the model is fixed, the left and right boundaries limit the displacement in the horizontal direction, and the slope is a free boundary. Set the set flow steady command to simulate the steady flow and the bound pp paygrade command to change the fluid pressure to simulate heavy rainfall. The model boundary constraints are shown in Figure 6. As shown, the mechanical parameters of rock mass materials are shown in Table 2. According to the established model, proceed to the next calculation.

\subsection{Analysis of Numerical Simulation Results}

\subsubsection{Displacement Analysis}

(1) Displacement Analysis in the Vertical Direction.

(2) Analysis of Displacement in the Horizontal Direction. It can be seen from Figures 7 and 8 that the displacement in the vertical direction is the largest at the top of the slope, and it gradually decreases in the downward direction of the sliding body. After 80,000 steps of simulated rainfall, the sliding body above the interlayer fracture zone has moved to different degrees. The maximum vertical displacement of the sliding body is about $0.4 \mathrm{~m}$, and only a small area has local sliding. Mainly concentrated on the top of the slope, at this time, there is no obvious cracking at the top of the slope. After 160,000 steps of simulated rainfall, the sliding body has already slid in a wide range, and the maximum displacement of the sliding body in the vertical direction is up to $1 \mathrm{~m}$. The sliding body slides down under the combined action of gravity and rain, and there is an obvious occurrence at the top of the slope. Cracking at the top of the slope intensifies the infiltration of rainwater and accelerates the occurrence of landslides. It can be seen from Figures 9 and 10 that in the horizontal direction, the maximum displacement occurs at the position of the slope toe and gradually decreases in the upward direction of the sliding body. When the simulated rainfall runs for 80,000 steps, horizontal sliding occurs at the position of the slope foot. After the simulated rainfall runs for 
TABLE 2: Basic mechanical characteristic parameters of materials.

\begin{tabular}{|c|c|c|c|c|c|c|}
\hline & Density $\left(\mathrm{kg} / \mathrm{m}^{3}\right)$ & $\begin{array}{l}\text { Bulk modulus } \\
\text { (Gpa) }\end{array}$ & $\begin{array}{l}\text { Shear modulus } \\
\text { (Gpa) }\end{array}$ & $\begin{array}{c}\text { Internal friction } \\
\text { angle }\left(^{\circ}\right)\end{array}$ & $\begin{array}{c}\text { Cohesion } \\
\text { (Mpa) }\end{array}$ & $\begin{array}{c}\text { Tensile strength } \\
\text { (Mpa) }\end{array}$ \\
\hline Moderately weathered tuff & 2470 & 20.2 & 8.1 & 33.2 & 38.4 & 16.5 \\
\hline Moderately weathered sandstone & 2660 & 26.4 & 10.8 & 45.3 & 41.3 & 21.5 \\
\hline Interlayer fracture zone & 1280 & 7.3 & 2.7 & 21.5 & 16.7 & 6.9 \\
\hline Strongly weathered tuff & 2320 & 17.5 & 6.5 & 26.2 & 23.8 & 13.8 \\
\hline Ravel cohesive soil & 1850 & 11.2 & 3.5 & 25.3 & 19.5 & 8.6 \\
\hline
\end{tabular}
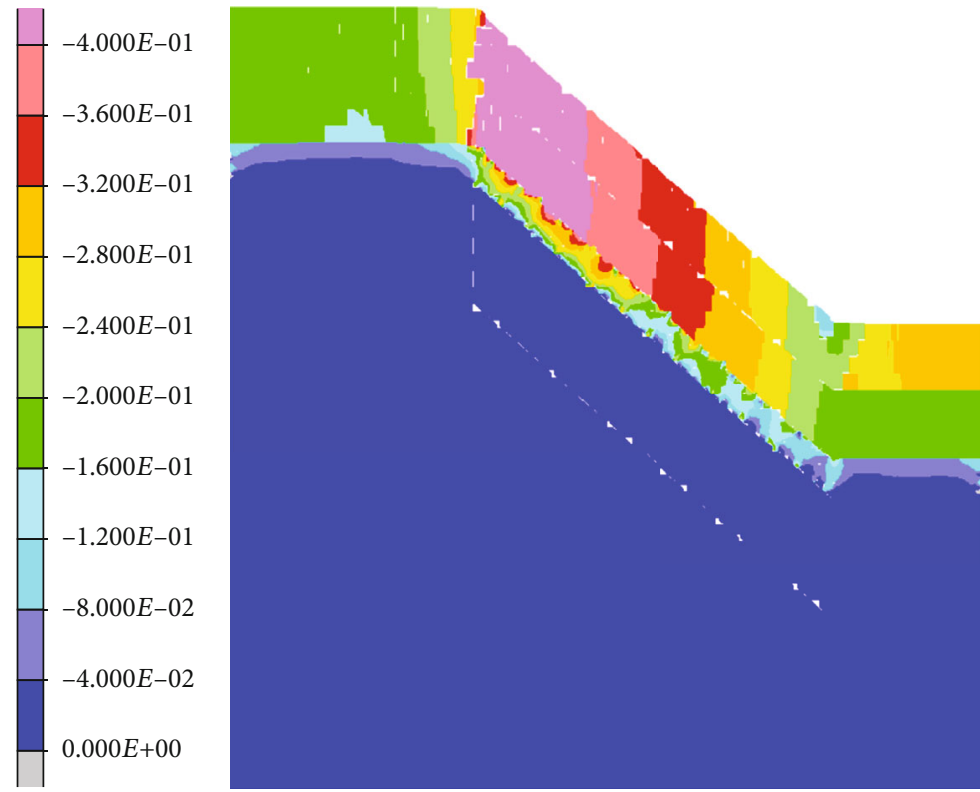

FIGURE 7: Displacement cloud diagram in the $y y$ direction when running 80,000 steps.
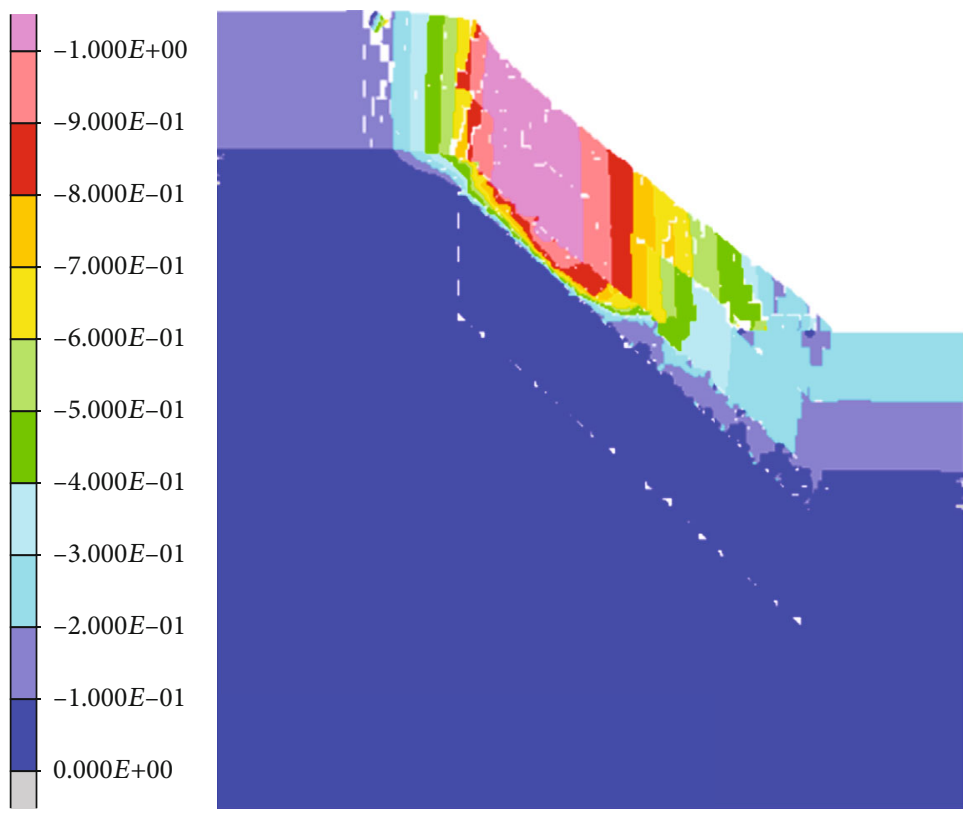

FIGURE 8: Displacement cloud diagram in the $y y$ direction when running 160,000 steps. 


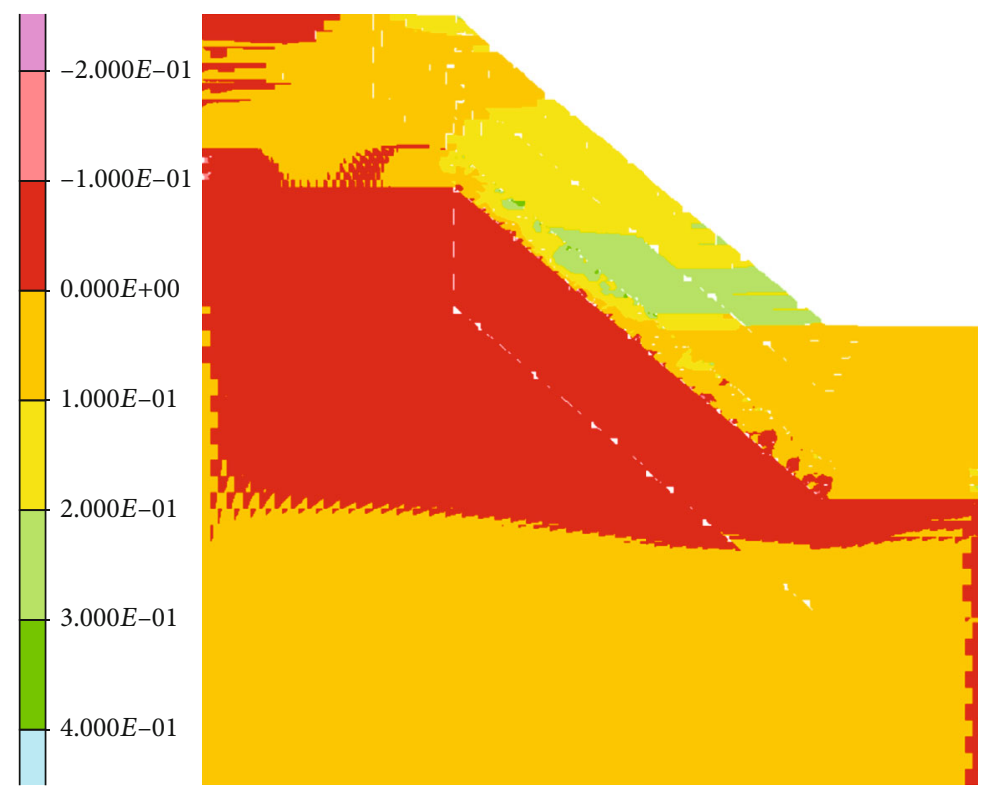

Figure 9: Displacement cloud diagram in the $x x$ direction when running 80,000 steps.

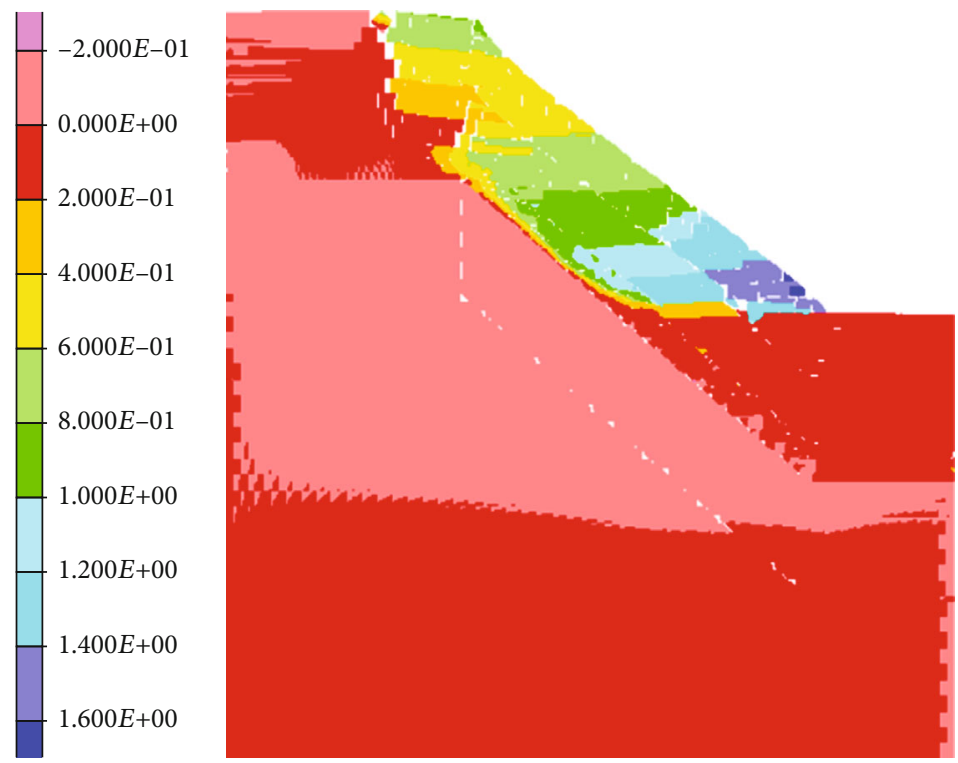

Figure 10: Displacement cloud diagram in the $x x$ direction when running 160,000 steps.

160,000 steps, due to the further infiltration of rainwater, the sliding body has a large-scale sliding in the horizontal direction. The amount of slippage reaches 1.5 meters. At this time, the slope has a wide range of slippage and the slippage distance is large. To sum up, under the rainfall conditions of the slope, as the rainfall time passes, the rainwater continuously penetrates into the rock and soil, and the strength of the rock and soil decreases. After reaching the critical rainfall, the slope slides in a wide range, which finally led to the occurrence of landslides. The slope stability is greatly reduced during rainfall. In the process of continuous rainfall, the trailing edge of the sliding body undergoes shear creep, and a nearly vertical tension crack is formed at the sliding surface. As the infiltration increases, the sliding body slides in a wide range.

\subsubsection{Vector Analysis}

(1) Speed Vector Analysis.

(2) Displacement Vector Analysis. It can be seen from Figures 11 and 12 that with the passage of rainfall time, when running 80,000 steps and running 160,000, the displacement vector at the slope and the top and foot of the slope are consistent with the general trend of the speed vector, and the speed vector points to the position of the foot of the slope. And the vector is the largest at the foot of the slope. The magnitude of the speed vector when running at 80,000 steps is significantly smaller than the speed vector when running at 160,000 steps, mainly because the increase in rainwater infiltration will weaken the rock and soil properties. It can be seen 

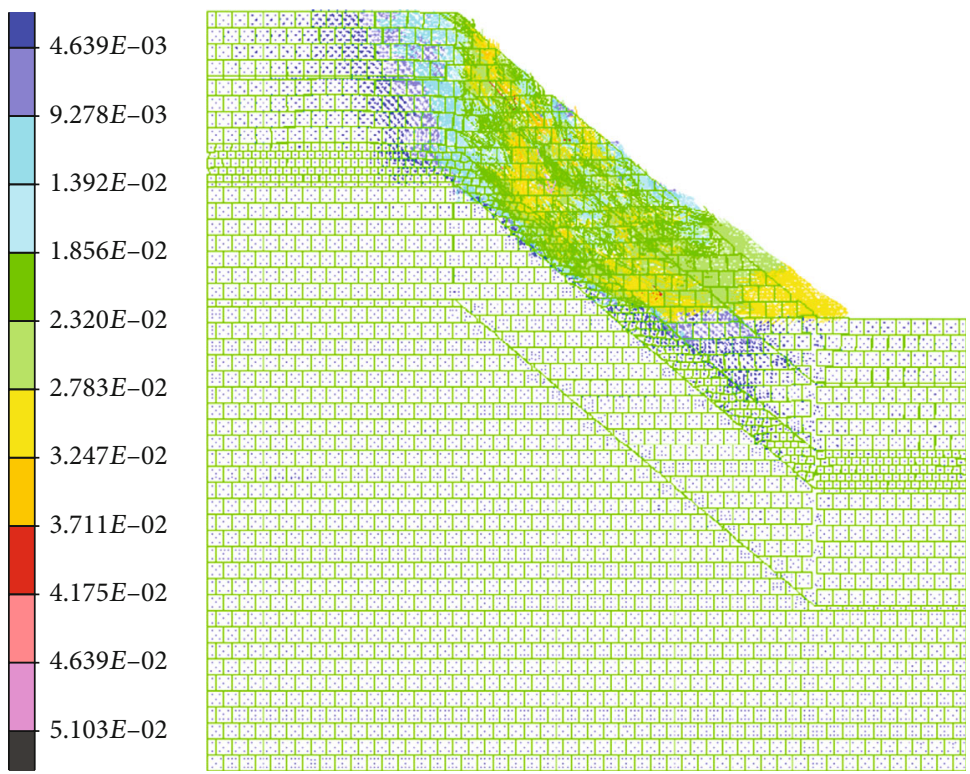

FIGURE 11: Speed vector diagram when running 80,000 steps.
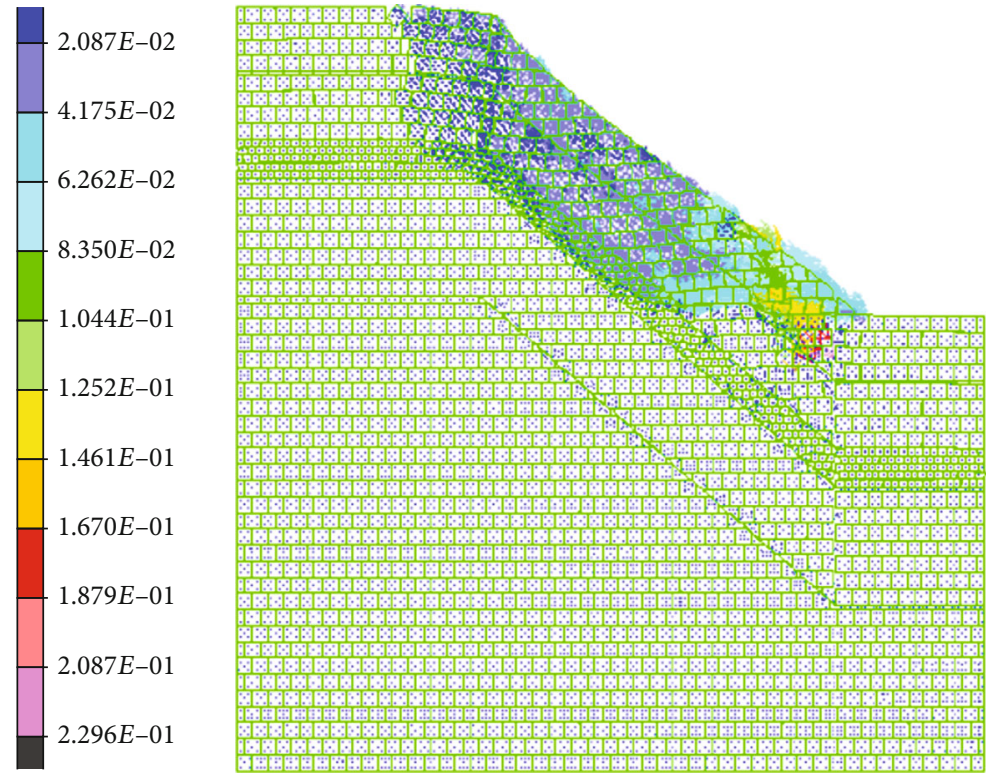

FIGURE 12: Speed vector diagram when running 160,000 steps.

from Figures 13 and 14 that when operating at 80,000, the displacement vector points to the position of the interlayer broken zone. At this time, tensile failure occurs at the top of the slope, and the slope tends to slide down the interlayer broken zone, and it is at the top of the slope. There is the greatest downward trend along the slope and the smallest at the foot of the slope. When it reaches 160,000 steps, the displacement vector points to the empty position of the slope. Due to the infiltration of rainfall, the sliding body slides as a whole. Affected by the gravity of the upper rock and soil mass and rainwater, the displacement vector is the largest near the interlayer fracture zone and the position of the slope toe, and the tendency of slippage is the largest at the position of the slope toe. During the sliding process, because the sliding body forms a certain accumulation in the lower part and has certain support to the upper part of the sliding body, the displacement vector at the upper part of the sliding body is small.

4.2.3. Displacement Analysis of Monitoring Points. To be able to more clearly analyze the displacement changes of the slope during the rainfall process, different monitoring points are set at the slope surface and the slope toe positions, four monitoring points are set at five equal positions on the slope surface, and four monitoring points are set at the middle position of each rock layer in the vertical direction at the bottom of the slope, and the monitoring point positions are set as shown in Figure 15. 


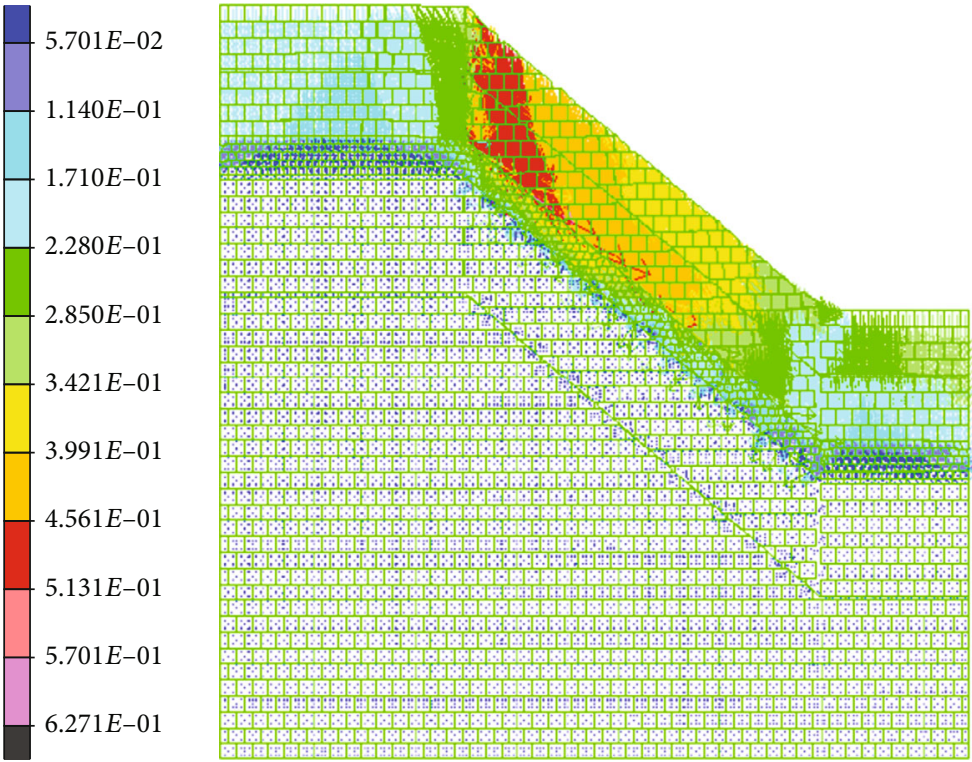

FIGURE 13: Displacement vector diagram when running 80,000 steps.
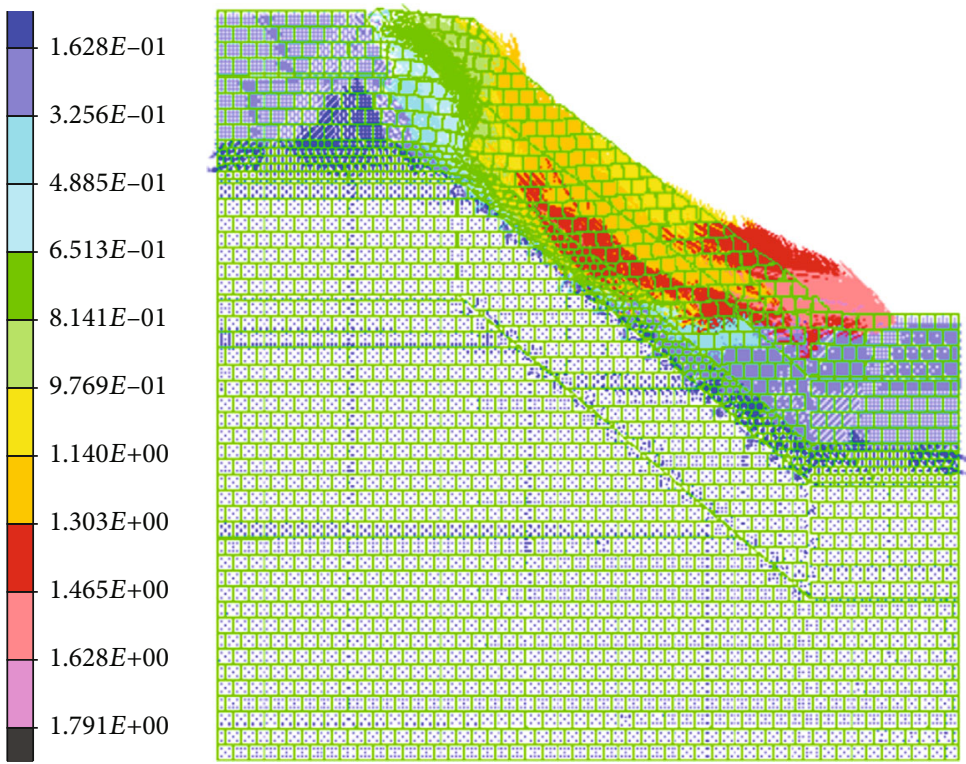

FIGURE 14: Displacement vector diagram when running 160,000 steps.

(1) Analysis of Point Displacement in Slope Monitoring. The displacement of each monitoring point in the horizontal and vertical directions is derived, and the relationship between each monitoring point and the number of running steps is obtained, as shown in Figures 16 and 17.

Figure 16 shows that in the early stages of the rainfall, the horizontal displacement of slope monitoring did not change; with the increase of rainfall time, running to 20000 steps, the first of the 4 \# monitoring point is near the location of the broken foot, creep, and in 20000 30,000 steps, it increases the speed of the maximum displacement, the first to appear stress concentration on the position of slope toe, and the basic is greater than the strength of the rock mass stress values, the rock mass damage in the slope foot position first, after running 30,000 steps, and the horizontal displacement monitoring points is at the same rate of increase, when running to 160,000 steps. The displacement of no. 4 monitoring point reaches $360 \mathrm{~mm}$; slope location of stress concentration first occurred in the slope rock mass, the slope foot began to destroy, and after the release of stress concentration, the weak release in the near surface to form a new stress concentration occurs when running to 30,000 steps, and 1 3 \# monitoring points began to creep in the horizontal direction, and the whole slope is at unstable stage, and with the increase of rainfall, slope surface individual monitoring station started rising, running to 160,000 steps, $1 \sim 3$ \# in the horizontal displacement of monitoring points are, respectively, $170 \mathrm{~mm}$, 


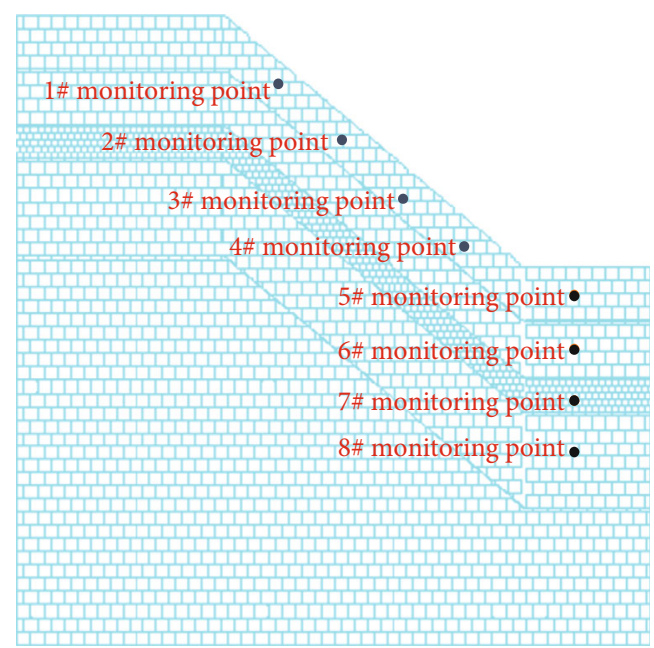

FIGURE 15: Schematic diagram of monitoring point setting.

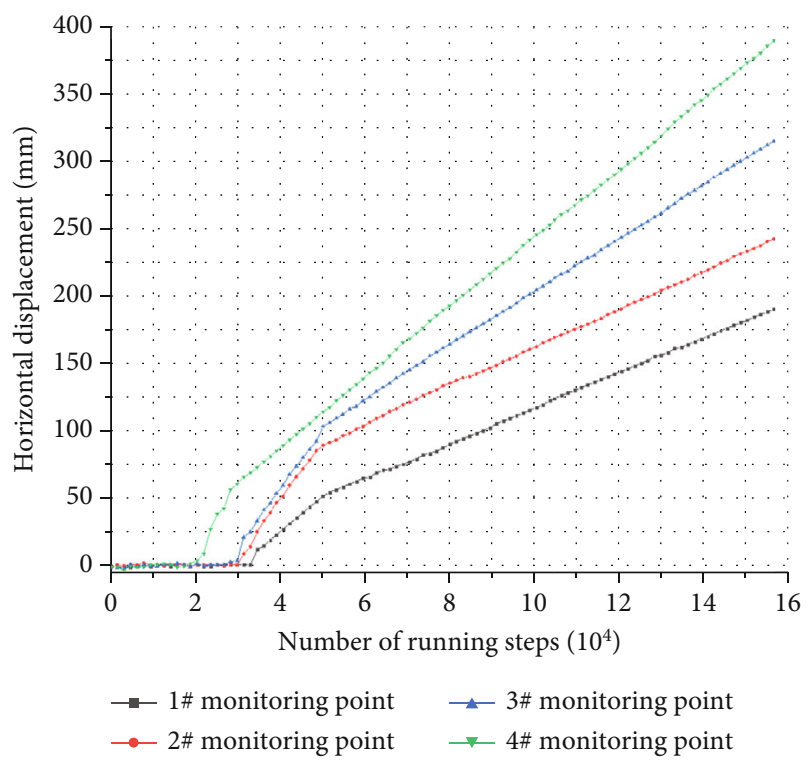

Figure 16: Horizontal displacement changes of slope monitoring points.

$240 \mathrm{~mm}$, and $315 \mathrm{~mm}$. Figure 17 shows that in the vertical direction, at the beginning of the run, because the rain infiltration quantity is less, it has little impact on the stability of the slope as a whole; therefore, the initial displacement has no increase between 20000 and 50000 steps, and the internal of slope rock mass due to a long time of soaking starts a largescale move down the slope in the vertical direction, and at the end of the run, vertical displacements of slope surface 1 4 \# monitoring sites were up to $580 \mathrm{~mm}, 505 \mathrm{~mm}, 405 \mathrm{~mm}$, and $300 \mathrm{~mm}$.

(2) Displacement Analysis of the Monitoring Point of the Slope Foot. It can be seen from Figures 18 and 19 that after running 30,000 steps at measuring points 5\# and 6\#, the displacement in the horizontal and vertical directions began to increase significantly, mainly due to the overall sliding of the upper slid-

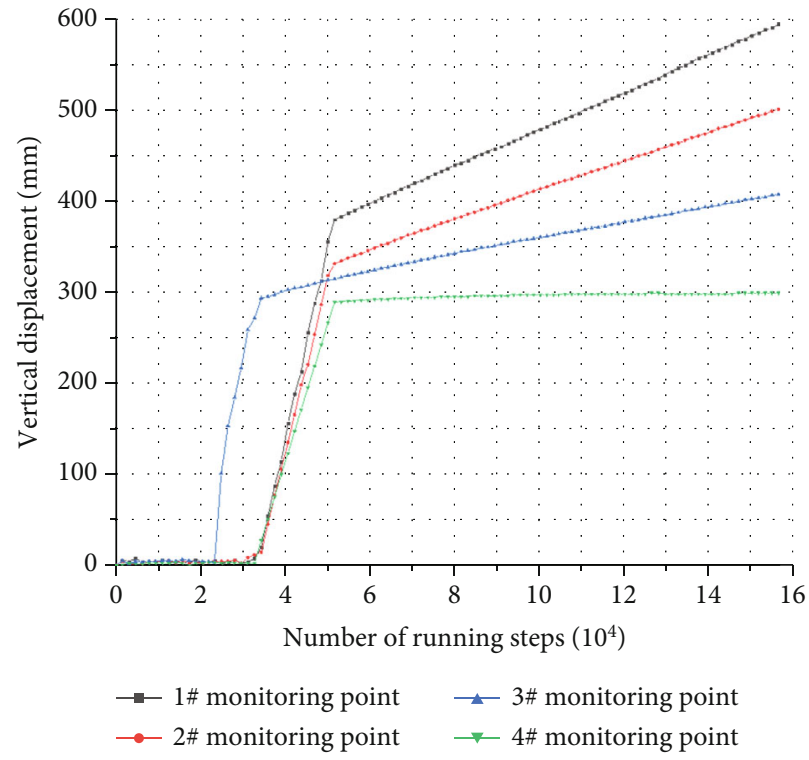

FigURE 17: Vertical displacement change of slope monitoring point.

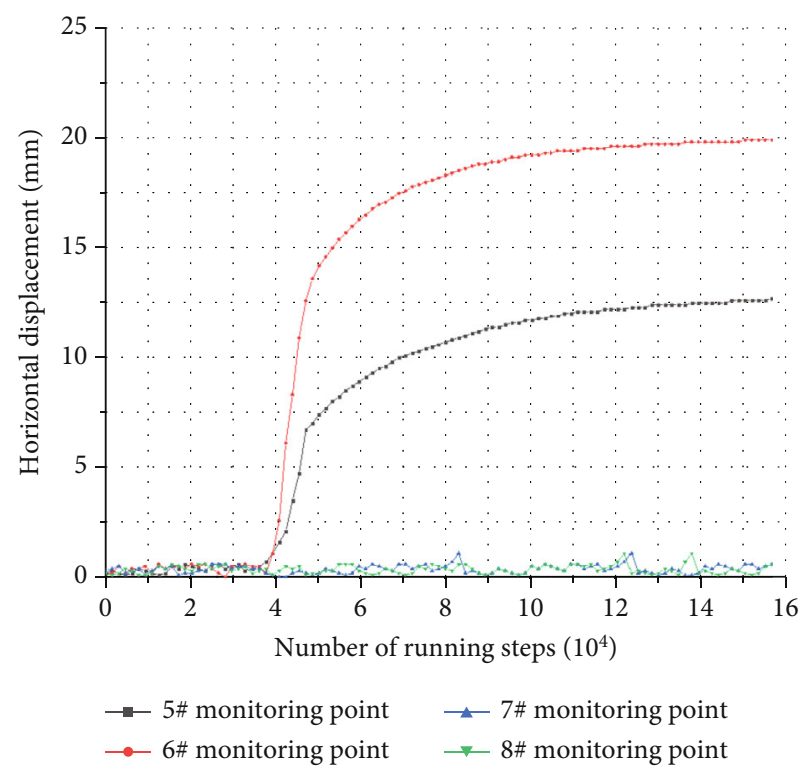

FIgURe 18: Horizontal displacement change of the slope foot monitoring point.

ing body, which has a certain impact on the bottom of the slope. Squeezing leads to increased displacement in the horizontal and vertical directions. In the early stage, when the sliding surface starts to slip, the rock and soil at the bottom of the slope have certain fissures, and they begin to become dense under the extrusion of the upper sliding body. When the rock and soil at the bottom of the slope are gradually compacted, the two, the displacement of the measuring point position is not changing. Because the $7 \#$ and $8 \#$ measuring points are in the interlayer fracture zone and its lower part, and the sliding body is on and above the interlayer fracture zone, and it does not affect the measuring point below the slope, so the displacement of the measuring point is unchanged. 


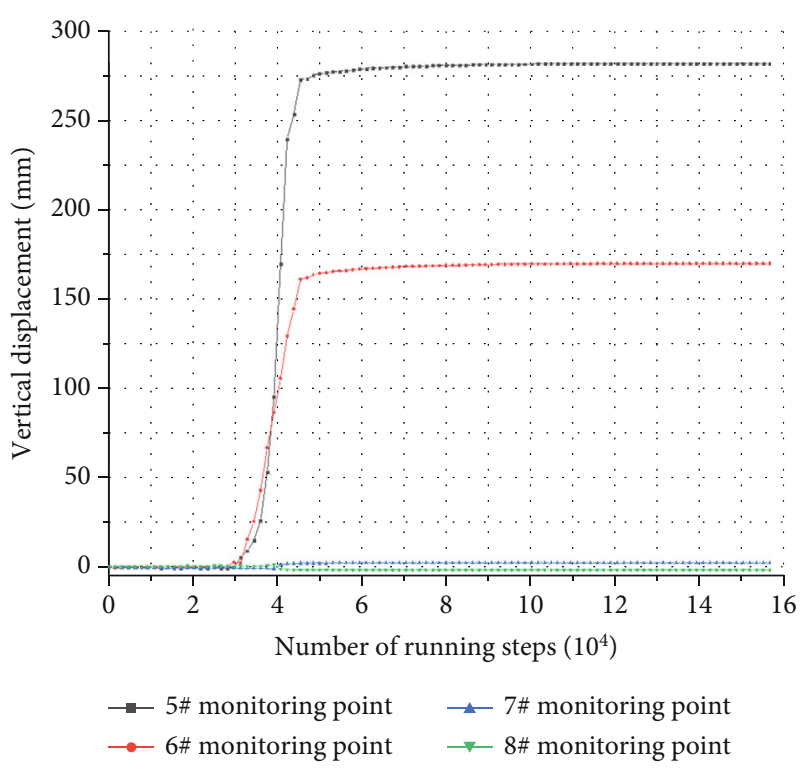

Figure 19: Vertical displacement change of the slope foot monitoring point.

\section{Slope Physical Model Experiment under Heavy Rainfall}

The physical model test adopts the "Physical Model Test System for the Destructive Structure Effect of Deep Underground Engineering". The maximum external dimensions of the model device are length $\times$ width $\times$ height $=1.6 \mathrm{~m} \times$ $1.6 \mathrm{~m} \times 0.4 \mathrm{~m}$, the maximum load of the model boundary is $5 \mathrm{MPa}$, and the load concentration is uneven. Less than $1 \%$, the model boundary can be stabilized for more than 48 hours. At the same time, a three-dimensional full strain measurement system (DIC) is used for data collection and monitoring of the whole process.

5.1. Similar Model Experiment. The experimental materials are barite powder, gypsum, quartz sand, water, and gypsum retarder commonly used in physical model experiments and are equipped according to a certain proportion. Among them, quartz sand and barite powder are aggregates, and gypsum plays a binding role. The gypsum retarder prolongs the setting time of the gypsum without affecting the other properties of the gypsum and facilitates the pouring of the model. After the selection of similar materials, the material ratio needs to be determined [25-27]. The ratio of similar materials is the key factor of the model test. The model test materials must meet the requirements of similar principles. In the existing research on similar materials, similar conditions are met in parameters such as density, cohesion, and elastic modulus, and the strength and deformation characteristics of similar materials under complex stress conditions are ignored [28-33]. According to the selected materials, combined Ning et al., Zhang et al., Zhan et al., etc. related to the research results of similar materials in the slope physical model test, combined with the orthogonal design method to study the ratio of similar materials, and determined barite powder:sand:gypsum, respectively, it is prepared in the

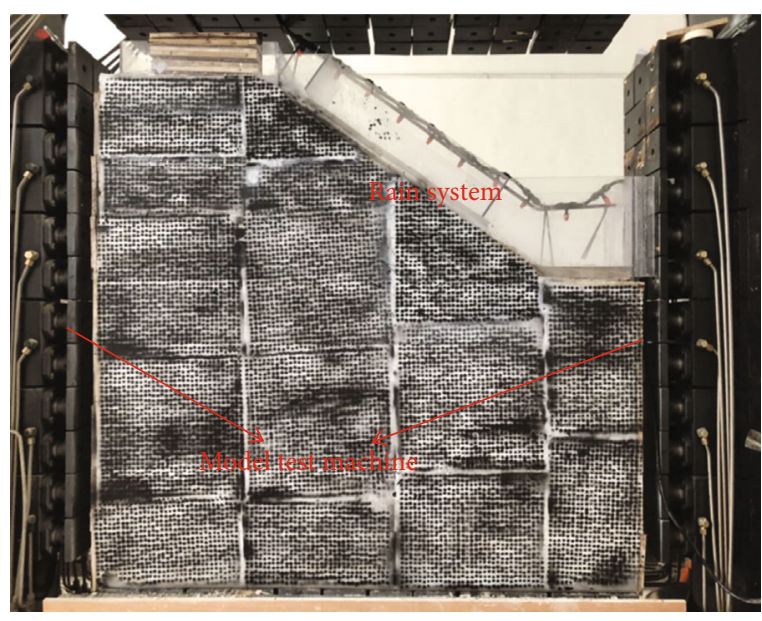

FIgURe 20: Model experiment system.

ratio of $1: 8: 1,2: 7: 1,3: 6: 1$, and $4: 5: 1$, and the content of gypsum retarder is $2 \%$ of the amount of gypsum.

According to the abovementioned mixing ratio of similar materials, the model adopts a continuous pouring layer by layer. After layering and tamping, dry barite powder is sprinkled to simulate interlayer joints. After pouring, the model is shown in Figure 20. After pouring is completed under ventilated conditions after curing, the next stage of the experiment will begin after the model is completely hardened. Before the start of the experiment, the simulated rainfall system was installed on the slope model. During the experiment, a three-dimensional full strain measurement system (DIC) was used to monitor the whole process. The left and right boundaries of the model were applied with a force of $0.1 \mathrm{MPa}$, and the upper boundary of the model was applied at the top of the slope. With a force of $0.1 \mathrm{MPa}$, the force in all directions is always at a constant load. According to the regulations of China National Meteorological Administration, according to the daily rainfall ID, it is divided into the following: ID $>100 \mathrm{~mm}$ for torrential rain, $50 \mathrm{~mm}>\mathrm{ID}>$ $100 \mathrm{~mm}$ for heavy rain, $25 \mathrm{~mm}>$ ID $>50 \mathrm{~mm}$ for moderate rain, and $\mathrm{ID}<25 \mathrm{~mm}$ for medium-light rain. According to this, the rainfall system and monitoring system are designed. The rainfall system is shown in Figure 21. The system mainly simulates the conditions of a heavy rainstorm, and the simulated rainfall is controlled at $240 \mathrm{~mm} / \mathrm{d}$. The rainfall system includes sprinkler, flow monitor, water pump controller, water pump, and connected water pipe and uses DIC to record the changes of the physical model throughout the process as shown in Figure 22.

\subsection{Analysis of Experimental Results}

5.2.1. Macro Analysis. Figure 23 shows the state after the model experiment is destroyed during the experiment. In the initial stage in the process of continuous rainfall, due to less rainfall, rainfall did not reach interlayer fracture zone of slope position, and slope is in steady state; as time goes on, rainfall infiltration and rainfall infiltration part are continuously thorough to the inside slope until you reach interlayer fracture zone position; due to poor interlayer fracture 


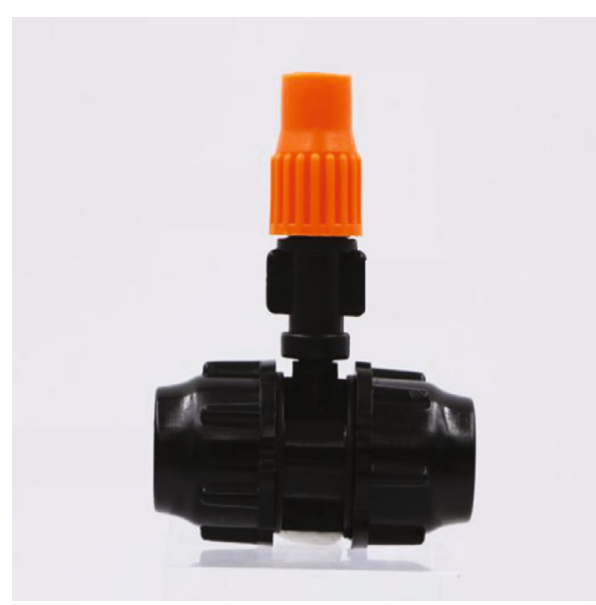

(a)

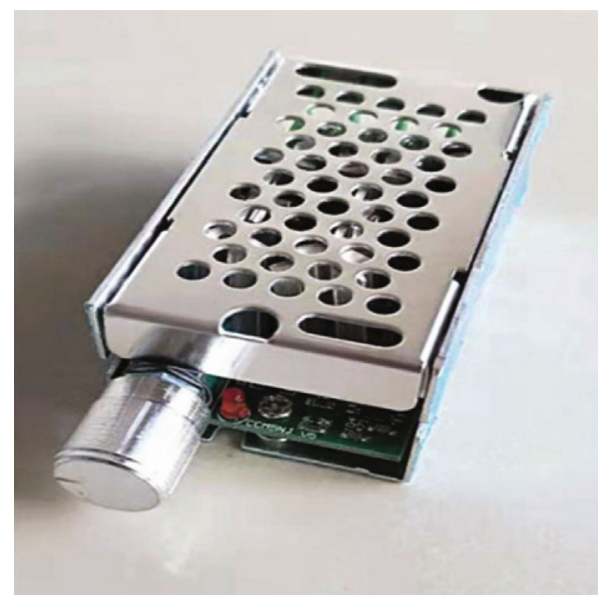

(c)

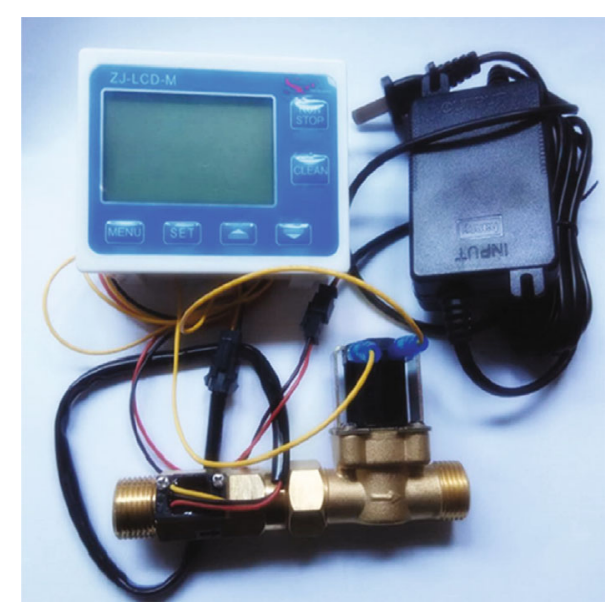

(b)

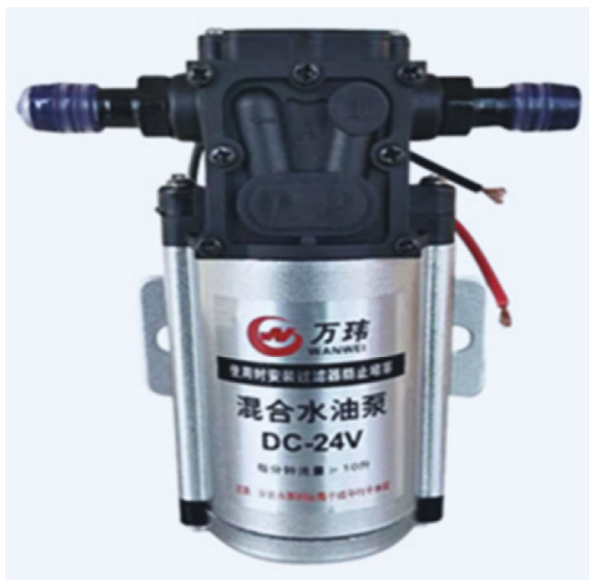

(d)

FIgURE 21: Rainfall and monitoring system.

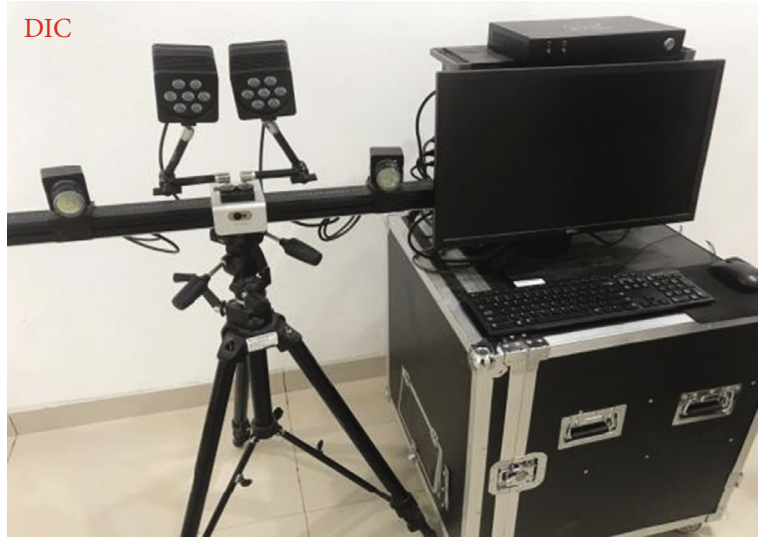

FIGURE 22: Experimental monitoring system.

zone location lithology, coupled with the rain infiltration, the slope body weight increased, which leads to a decrease of slope sliding resistance; in the rain after reaching a certain degree, the internal cracks of slope in the interlayer fracture zone crack until, eventually leads to the occurrence of landslides.

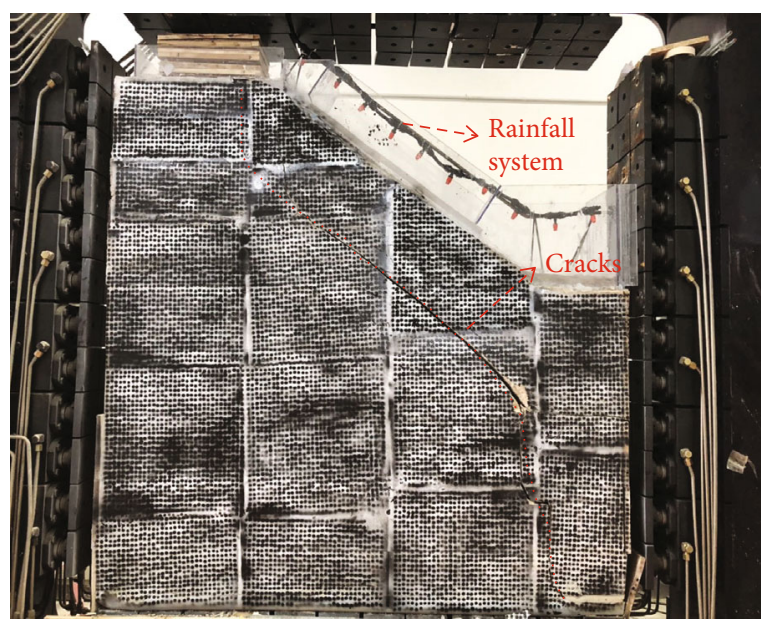

Figure 23: Slope model after the landslide.

5.2.2. Strain Analysis. The strain change during the whole process of landslide under heavy rainfall conditions is shown in Figure 24. When the continuous rainfall time is $1 \mathrm{~h}$, there is 


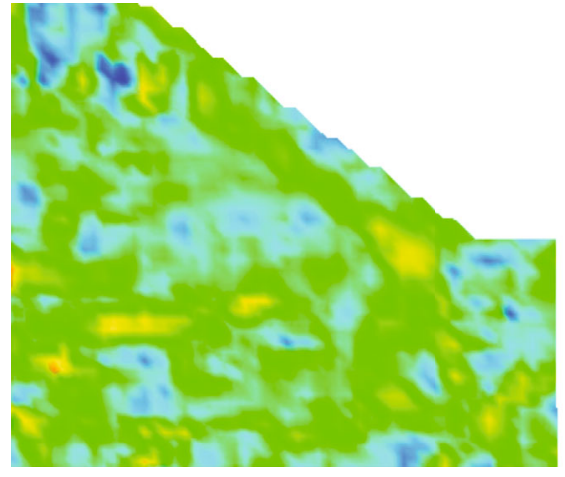

(a) Rainfall $1 \mathrm{~h}$

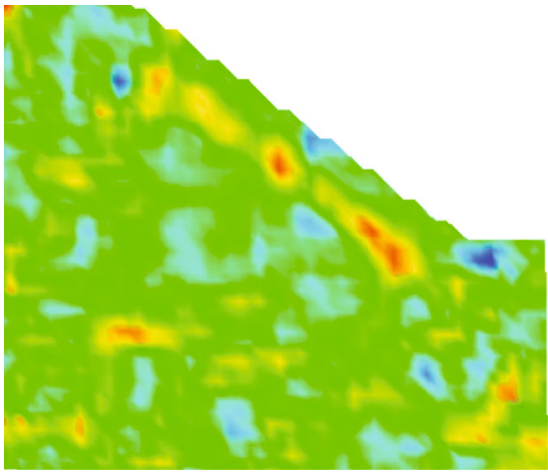

(c) Rainfall $3 \mathrm{~h}$

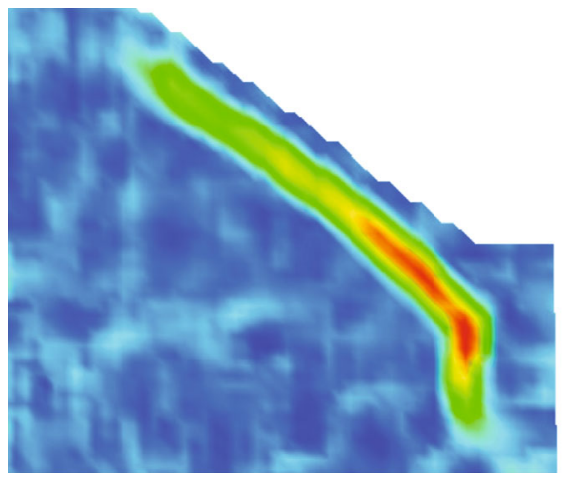

(e) Rainfall $5 \mathrm{~h}$
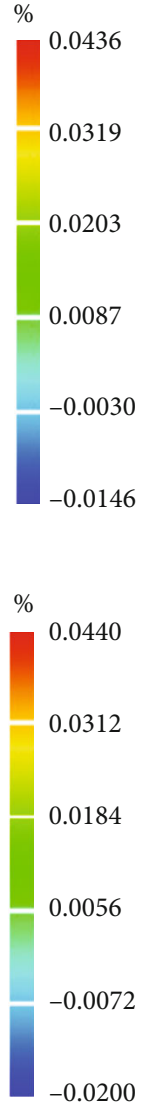

$-0.0200$

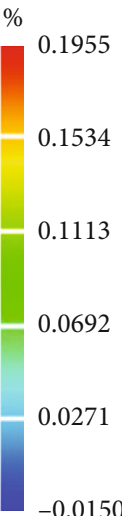

$-0.0150$

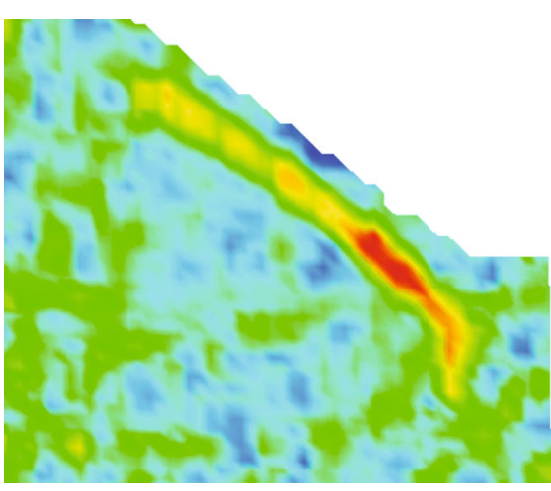

(d) Rainfall $4 \mathrm{~h}$

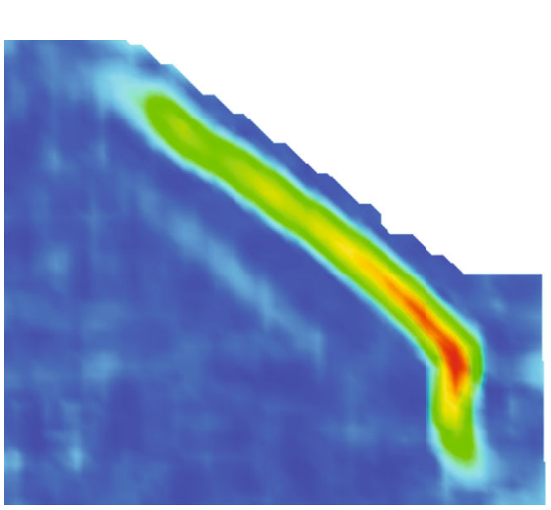

(f) Rainfall $6 \mathrm{~h}$

0.0462

0.0346

0.0230

0.0114

$-0.0002$

$-0.0118$
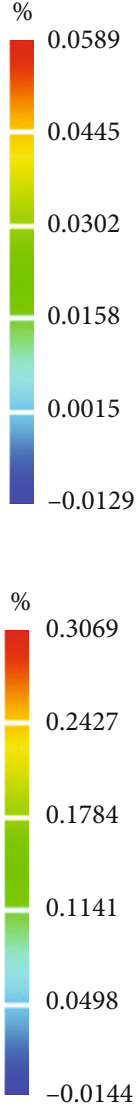

$-0.0144$

Figure 24: Continued. 


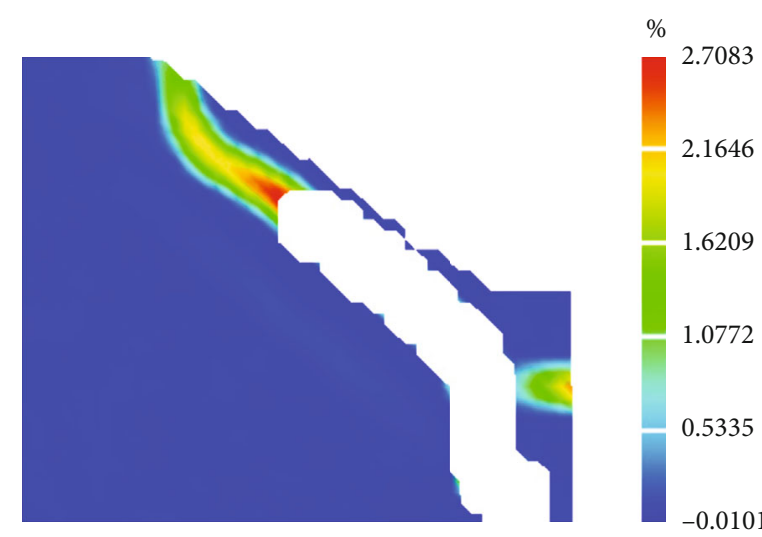

(g) Rainfall $7 \mathrm{~h}$

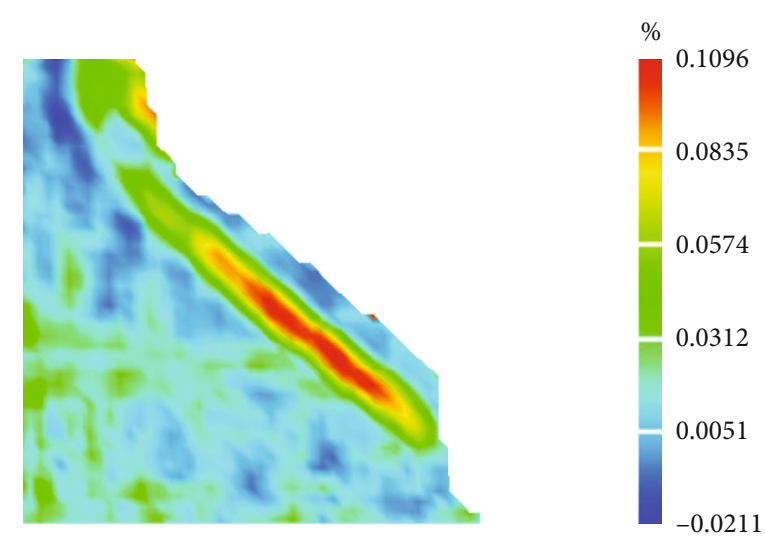

(h) Rainfall $8 \mathrm{~h}$

Figure 24: Slope strain changes under extreme rainfall conditions.

no obvious strain increase area inside the slope, indicating that the rainfall only infiltrates the shallow part of the slope during this stage at the surface layer, and rainfall has little effect on the stability of the slope at this time. The strain in the local area of the slope increases, but the increase is small, mainly due to the small cracks in the model during the pouring process, and the local cracks continue the strain increases during full load, as shown in Figure 24(a). When the continuous rainfall lasts for 2 hours, due to the accumulation and infiltration of rainwater at the toe of the slope, and the toe of the slope is in the empty state, firstly, a sudden increase in strain is formed at the toe of the slope, and the strain in other areas has little change. As shown in Figure 24(b). When the continuous rainfall lasts for 3 hours, the rainfall is relatively large, and with time, rainwater gradually penetrates from the surface to the interlayer fracture zone area, the interlayer fracture zone area is continuously softened, and the internal cracks of the model are filled with water. The strain gradually increases in the fractured region between layers, as shown in Figure 24(c).

When the continuous rainfall time is 4 hours, the rainfall has reached $40 \mathrm{~mm}$ at this time, and the rainfall has infiltrated into the interlayer fracture zone. The strain near the interlayer fracture zone has increased significantly. With the infiltration of a large amount of rainfall, the interlayer fracture, the mechanical properties of the rock, and soil mass in the zone began to decrease, and the model formed cracks near the interlayer fracture zone and gradually developed towards the top of the slope, as shown in Figure 24(d). When the continuous rainfall time is $5 \mathrm{~h}$, the interlayer fracture zone area is basically in a saturated state. At this time, after the rainfall infiltrates the slope, the slope's weight is continuously increasing, increasing the sliding force, the mechanical properties of the rock and soil are changing, and the strength is constant. The crack decreases and penetrates, as shown in Figure 24(e). When the continuous rainfall time is $6 \mathrm{~h}$, the rainfall has reached $60 \mathrm{~mm}$ at this time, the slope is already in a saturated state, and the fractured zone between the layers has completely penetrated, as shown in Figure 24(f). When the continuous rainfall time is $7 \mathrm{~h}$, the total rainfall is $70 \mathrm{~mm}$ at this time, and the strain of the slip surface after the penetration within this time continues to increase until a large-scale landslide occurs in the model, as shown in Figure 24(g). After the landslide occurred, the rainfall continued for 1 hour. At this time, due to the first landslide, the original stable slope was in a state of airspace, and a large amount of rainwater infiltrated through the cracks, resulting in an unstable position of the original stable slope, as shown in Figure 24(h).

\section{Conclusion}

(1) Through numerical simulation of slope stability under heavy rainfall conditions, at the beginning of rainfall, the slope displacement did not change. As time delays, creeping occurs first at the toe of the slope and repeated occurrences at the toe of the slope. Stress concentration and stress release caused the slope to slide as a whole, and the vertical displacements of the monitoring points on the slope surface $1 \#, 2 \#, 3 \#$, and $4 \#$ reached $580 \mathrm{~mm}, 505 \mathrm{~mm}$, $405 \mathrm{~mm}$, and $300 \mathrm{~mm}$, respectively

(2) Established a slope physical experiment model under heavy rainfall conditions, and the experimental system can meet the requirements of heavy rainfall experiments

(3) Through the physical model test on the slope of Shangge Village under heavy rainfall conditions, the whole process of slope instability and failure under heavy rainfall conditions is simulated. Under $240 \mathrm{~mm} / \mathrm{d}$ rainfall conditions, when the continuous rainfall is $20 \mathrm{~mm}$, first, an area of the sudden increase in strain is formed at the foot of the slope. As the rainfall continues, rainwater gradually penetrates from the surface to the area of the interlayer fracture zone, the area of the interlayer fracture zone is continuously softened, and the strain of the interlayer fracture area gradually increases; when the rainfall reaches $40 \mathrm{~mm}$, cracks are formed near the broken zone between the layers of the model and gradually 
extend to the top of the slope; when the rainfall is $70 \mathrm{~mm}$, a thorough crack is formed in the broken zone between the layers, and the slope becomes unstable

(4) The experimental results show that the physical model experiment and the numerical simulation result are more consistent, which can provide a basis for slope support and landslide disaster warning under heavy rainfall conditions

\section{Data Availability}

The data are available and explained in this article; readers can access the data supporting the conclusions of this study.

\section{Conflicts of Interest}

The authors declare that there is no conflict of interests regarding the publication of this paper.

\section{Acknowledgments}

This study is supported by the National Natural Science Foundation of China (Grant Nos. 51904188 and 41602308) and Open Fund Project of State Key Laboratory of Deep Geotechnical Mechanics and Underground Engineering, China (Grant No. SKLGDUEK1821).

\section{References}

[1] National Geological Hazard Bulletin, Ministry of Land and Resources of the People's Republic of China, 2017.

[2] National Geological Hazard Bulletin, Ministry of Land and Resources of the People's Republic of China, 2018.

[3] National Geological Hazard Bulletin, Ministry of Land and Resources of the People's Republic of China, 2019.

[4] Z. Liangtong, L. He, and C. Yunmin, "DGFredlund. Analysis of influencing factors of rain intensity-duration curve of rainfall-induced landslide forecast in the residual land area of southeast coast," Rock and Soil Mechanics, vol. 33, no. 3, pp. 872-880+886, 2012.

[5] H. Runqiu, "Large-scale landslides and their occurrence mechanism in China since the 20th century," Chinese Journal of Rock Mechanics and Engineering, vol. 26, no. 3, pp. 433-454, 2007.

[6] Y. Zheng, C. Zuyu, and G. Wang, etc. Slope and Landslide Management (Second Edition), People's Communications Publishing House, Beijing, 2010.

[7] J. L. Li, X. G. Hu, J. H. Xiong, and X. T. Yang, "Stability analysis and reinforcement optimization of the inlet slope of the Three Gorges Underground Power Station," Chinese Journal of Rock Mechanics and Engineering, vol. 5, pp. 676-679, 2001.

[8] L. Lei, K. L. Long, J. J. Wang, J. Zhang, and F. M. Huang, "Study on the dynamic evaluation of regional landslide hazard under the influence of rainfall: taking the main urban area of Wanzhou in the Three Gorges Reservoir area as an example," Chinese Journal of Rock Mechanics and Engineering, vol. 35, no. 3, pp. 558-569, 2016.

[9] N. Lai, Ryle. Principles of Geology, Peking University Press, 2008.
[10] Y. Zheng and Z. Shangyi, "Discussion on the safety factor in the engineering design of side (landslide) slope," Chinese Journal of Rock Mechanics and Engineering, vol. 9, pp. 1937-1940, 2006.

[11] A. W. Bishop, "The use of the slip circle in the stability analysis of earth slopes," Geotechnique, vol. 5, no. 1, pp. 7-17, 1955.

[12] Y. Zheng, S. Weimin, and M. Yang, "Discussion on unbalanced thrust method and Sarma method," Chinese Journal of Rock Mechanics and Engineering, vol. 17, pp. 3030-3036, 2004.

[13] C. Wang, M. He, and Q. Guo, "Systematic analysis of deformation and strength stability of high slopes in hydropower stations," Rock and Soil Mechanics, vol. 28, no. S1, pp. 581-585, 2007.

[14] B. Yu, Formation Mechanism and Prevention Countermeasures of Landslides in the Basalt Terrace Area of Zhejiang Province, Zhejiang University, 2006.

[15] Z. Lijie, H. Zhengjia, and L. Jing, "Application of FLAC3D in slope rock stability analysis," Rock and Soil Mechanics, vol. 26, no. S2, pp. 61-64, 2005.

[16] L. Huaizhong, H. Xie, J. He, and X. Mingli, "Slope sliding surface search method and dynamic stability analysis based on FLAC3D," Journal of Sichuan University (Engineering Science Edition), vol. 46, no. S1, pp. 111-115, 2014.

[17] N. Xu, T. Chunan, Z. Zhong, S. Chun, and Z. Liang, "Stability analysis of hydraulic rock slope based on 3D numerical simulation and microseismic monitoring," Chinese Journal of Rock Mechanics and Engineering, vol. 32, no. 7, pp. 1373-1381, 2013.

[18] N. Caine, "The rainfall intensity-duration control of shallow landslides and debris flows," Geografiska Annaler: Series A,Physical Geography, vol. 62, no. 1-2, pp. 23-27, 1980.

[19] Y. Wu, L. Hingxing, X. Gao, and L. Langping, "Research on the rainfall threshold curve of typhoon rain-type landslides: taking Fujian area as an example," Journal of Engineering Geology, vol. 22, no. 2, pp. 255-262, 2014.

[20] J. Xie, L. Liling, Y. Kunlong, D. Huiliang, and N. Xuexin, "Research on the rainfall threshold of landslide disaster warning and forecast in Zhejiang Province," Geological Science and Technology Information, vol. 4, pp. 101-105, 2003.

[21] Z. Heng, S. Erxiang, and M. Xu, "Slope stability analysis based on the extension of SMP criterion," Journal of Tsinghua University (Natural Science Edition), vol. 52, no. 2, pp. 150-154, 2012.

[22] T. Ping, L. Gang, and W. Xu, "Analysis of the influence of water and excavation unloading on the stability of rock slopes," Rock and Soil Mechanics, vol. 26, no. S2, pp. 21-24, 2005.

[23] H. Da and H. Runqiu, "Physical model test of fractured rock mass deformation failure and crack propagation evolution under unloading conditions," Chinese Journal of Rock Mechanics and Engineering, vol. 29, no. 3, pp. 502-512, 2010.

[24] Y. Wu, H. Siming, W. Dongpo, and L. Yu, "Fracture failure mechanism of rock slope under excavation unloading," Journal of Sichuan University (Engineering Science Edition), vol. 44, no. 2, pp. 52-58, 2012.

[25] N. Yibing, T. Huiming, Z. Bocheng, P. Shen, Z. Guangcheng, and X. Ding, "Research on rock similar material ratio based on orthogonal design and application of physical model test of bottom friction," Rock and Soil Mechanics, vol. 41, no. 6, pp. 2009-2020, 2020. 
[26] Z. Yanjun, N. Tingkai, L. Wang, and T. Jun, "Research on similar materials for physical model test of rock slopes," Journal of Southwest Jiaotong University, vol. 54, no. 1, pp. 55-60+72, 2019.

[27] Z. Zhifa, J. He, B. Zheng, and Q. Shengwen, "Experimental study on the ratio of similar materials in slope model," Progress in Geophysics, vol. 34, no. 3, pp. 1236-1243, 2019.

[28] Z. Li, H. Liu, Z. Dun, L. Ren, and J. Fang, "Grouting effect on rock fracture using shear and seepage assessment," Construction and Building Materials, vol. 242, p. 118131, 2020.

[29] Q. X. Meng, W. Y. Xu, H. L. Wang, X. Y. Zhuang, W. C. Xie, and T. Rabczuk, "DigiSim - an open source software package for heterogeneous material modeling based on digital image processing," Advances in Engineering Software, vol. 148, p. 102836, 2020.

[30] Q. Meng, H. Wang, M. Cai, W. Xu, X. Zhuang, and T. Rabczuk, "Three-dimensional mesoscale computational modeling of soil-rock mixtures with concave particles," Engineering Geology, vol. 277, article 105802, 2020.

[31] Z. G. Tao, C. Zhu, M. C. He, and M. Karakus, “A physical modeling-based study on the control mechanisms of negative Poisson's ratio anchor cable on the stratified toppling deformation of anti-inclined slopes," International Journal of Rock Mechanics and Mining Sciences, vol. 138, p. 104632, 2021.

[32] Y. Wang, B. Zhang, S. H. Gao, and C. H. Li, "Investigation on the effect of freeze-thaw on fracture mode classification in marble subjected to multi-level cyclic loads," Theoretical and Applied Fracture Mechanics, vol. 111, p. 102847, 2021.

[33] Z. Li, H. Zhou, D. Hu, and C. Zhang, "Yield criterion for rocklike geomaterials based on strain energy and CMP model," International Journal of Geomechanics, vol. 20, no. 3, article 04020013, 2020. 